\title{
Characterization of the Electrical Properties of Silicon Nanowire using the Dielectrophoretic Assembling Platform
}

\author{
Yen-Heng Lin ${ }^{1,2,3, *}$, Jing-Chao Wong ${ }^{2}$, Yong-Sheng Peng ${ }^{1}$ \\ ${ }^{1}$ Department of Electronic Engineering, Chang Gung University, Taoyuan 333, Taiwan \\ ${ }^{2}$ Graduate Institute of Medical Mechatronics, Chang Gung University, Taoyuan 333, Taiwan \\ ${ }^{3}$ Department of Otolaryngology-Head \& Neck Surgery, Chang Gung Memorial Hospital, Taoyuan \\ 333, Taiwan \\ *E-mail:yenheng@mail.cgu.edu.tw
}

doi: $10.20964 / 2017.09 .42$

Received: 11 April 2017 / Accepted: 7 July 2017 / Published: 13 August 2017

\begin{abstract}
In this study, the electrical properties of silicon nanowire were measured with a dielectrophoresis alignment platform. A pair of nickel electrodes spaced $10 \mu \mathrm{m}$ apart was fabricated on a quartz substrate using a lithography process. Then, silicon ( $\mathrm{Si}$ ) nanowires in the solution were attracted to the electrodes near them with an aid of dielectrophoretic force. As a result, Si nanowires that were longer than $10 \mu \mathrm{m}$ in length bridged the gap between the electrodes, forming a pair of Si nanowire sensors. Under an AC voltage with an amplitude of $10 \mathrm{Vpp}$ and a frequency of $100 \mathrm{kHz}$, approximately $20 \mathrm{Si}$ nanowires can bridge the gap between the electrodes within approximately $10 \mathrm{~s}$. After the solution evaporated, the Si nanowires were fixed by clamping them onto the upper and lower nickel electrodes using a second lithography process and a metal deposition process. Characterizations based on the current-voltage curve showed that this fixing process can reduce the contact resistance between the nickel and $\mathrm{Si}$ nanowires and allow an ohmic contact to form between them. Consequently, the properties of the devices became more stable, which verified the possibility of using the assembled $\mathrm{Si}$ nanowire sensors as biosensors.
\end{abstract}

Keywords: silicon nanowire, nanowire sensor, dielectrophoresis, microfabrication

\section{$\underline{\text { FULL TEXT }}$}

(C) 2017 The Authors. Published by ESG (www.electrochemsci.org). This article is an open access article distributed under the terms and conditions of the Creative Commons Attribution license (http://creativecommons.org/licenses/by/4.0/). 